\title{
Protective Effects of Lycium barbarum Extracts on UVB-Induced Damage in Human Retinal Pigment Epithelial Cells Accompanied by Attenuating ROS and DNA Damage
}

\author{
Feng-Chi Hsieh, ${ }^{1}$ Chun-Tzu Hung, ${ }^{1,2}$ Kai-Chun Cheng, ${ }^{3,4,5}$ Chang-Yi Wu, ${ }^{6,7}$ \\ Yen-Chun Chen, ${ }^{6}$ Yu-Jen Wu, ${ }^{8}$ Wangta Liu $\oplus^{6,9}$ and Chien-Chih Chiu $\oplus^{6,7,10,11,12}$ \\ ${ }^{1}$ Department of Radiology, Yuan's General Hospital, Kaohsiung 802, Taiwan \\ ${ }^{2}$ Department of Ophthalmology, Yuan's General Hospital, Kaohsiung 802, Taiwan \\ ${ }^{3}$ Department of Ophthalmology, Kaohsiung Municipal Hsiaokang Hospital, Kaohsiung 812, Taiwan \\ ${ }^{4}$ Department of Ophthalmology, Kaohsiung Medical University Hospital, 807 Kaohsiung, Taiwan \\ ${ }^{5}$ Department of Optometry, Shu-Zen Junior College of Medicine and Management, Kaohsiung 821, Taiwan \\ ${ }^{6}$ Department of Biotechnology, Kaohsiung Medical University, Kaohsiung 807, Taiwan \\ ${ }^{7}$ Department of Biological Sciences, National Sun Yat-sen University, Kaohsiung 804, Taiwan \\ ${ }^{8}$ Department of Nursing, Meiho University, Pingtung 912, Taiwan \\ ${ }^{9}$ Lipid Science and Aging Research Center, Kaohsiung Medical University, Kaohsiung 807, Taiwan \\ ${ }^{10}$ Research Center for Environment Medicine, Kaohsiung Medical University, Kaohsiung 807, Taiwan \\ ${ }^{11}$ Translational Research Center, Cancer Center, Department of Medical Research, Kaohsiung Medical University Hospital, \\ Kaohsiung Medical University, Kaohsiung 807, Taiwan \\ ${ }^{12}$ Graduate Institute of Medicine, College of Medicine, Kaohsiung Medical University, Kaohsiung 807, Taiwan
}

Correspondence should be addressed to Wangta Liu; liuwangta@kmu.edu.tw and Chien-Chih Chiu; cchiu@kmu.edu.tw

Received 12 February 2018; Revised 21 August 2018; Accepted 3 September 2018; Published 7 November 2018

Academic Editor: Francisco J. Romero

Copyright (C) 2018 Feng-Chi Hsieh et al. This is an open access article distributed under the Creative Commons Attribution License, which permits unrestricted use, distribution, and reproduction in any medium, provided the original work is properly cited.

The medicinal herb Lycium barbarum fruit has been widely used for improving and maintaining the health of the eyes in the Far East for many centuries. This study is aimed at investigating whether protective effects generated from the aqueous (LBA) and ethanol (LBE) extracts of the L. barbarum fruit existed against oxidative stress-induced apoptosis in human retinal pigment epithelial cells. L. barbarum extracts LBA and LBE exerted the activity of ROS scavenging and rescued UVB irradiation-induced growth inhibition in retinal pigment epithelial ARPE-19 cells. Compared to LBA, the ethanol extract LBE exerted a superior protective activity on UVB-induced growth arrest in ARPE-19 cells. Both L. barbarum extracts significantly reduced cell cycle $\mathrm{G}_{2}$-arrest population in ARPE-19 cells. Furthermore, the cytometer-based Annexin V/propidium iodide staining assay further showed that both L. barbarum extracts protected ARPE-19 cells from UVB-induced apoptosis. L. barbarum extracts also reduced the activation of $\gamma \mathrm{H} 2 \mathrm{AX}$, a sensor of DNA damage in ARPE-19 cells in a dose-responsive manner. By using Ingenuity Pathway Analysis (IPA), the bioinformatics revealed that the protective effects of both LBA and LBE extracts might be involved in three signaling pathways, especially the Toll-like receptor (TLR) pathway associated with cellular proliferation. Our study suggests that both ethanol and aqueous extracts of L. barbarum exhibit antioxidant activity and rescue UVB-induced apoptosis of ARPE-19 cells. Collectively, the ethanol extract exerts a superior effect on rescuing UVB-induced growth arrest of ARPE-19 compared to the aqueous extract, which might be associated with the activation of TLR signaling. Our present work will benefit the preventive strategy of herbal medicine-based vision protection for treating eye diseases such as age-related macular degeneration in the future. 


\section{Introduction}

Age-related macular degeneration (AMD), a progressive macular retinal disease with degenerative changes, can be divided into atrophic and exudative, characterized by the progressive atrophy of retinal pigment epithelial (RPE) cells and the formation of choroidal neovascularization (CNV) [1]. RPE cells are located between the layers of photoreceptor cells and provide nutrition to the latter. If oxidative damage occurs in RPE cells, the breakdown of photoreceptor cells would quickly follow and visual acuity might become damaged [2].

The fruit of Lycium barbarum (LB) wolfberry is a traditional Chinese herbal medicine that has multiple functions in pharmacology [3] like antioxidation [4-6], antiaging [7, 8], neuroprotection [9-12], cytoprotection [13, 14], and immunomodulating $[5,15]$. A previous study showed that LBP (Lycium barbarum polysaccharides) extracted from the fruit of $L$. barbarum might be responsible for the above biological activities [16]. LBP was also shown to exert a protective effect against oxidative damage in cells [17-20]. Based on the antioxidant activity of L. barbarum, many studies have demonstrated that LBP has a protective effect against oxidative injury in cells [17-20], and many studies have focused on the bioactivities of this extract of $L$. barbarum. However, the effects of the ethanol fraction of LB extracts have been little addressed by previous studies. In the study, we prepared both aqueous (LBA) and ethanol (LBE) extracts of LB and investigated the protective effects of LBA or LBE on human retinal pigment epithelial (ARPE-19) cells from UVB damage, notably proliferation inhibition and apoptosis. We also discussed the possible mechanism underlying $L$. barbarum extract-mediated protective effect on retinal pigment epithelial cells.

\section{Materials and Methods}

2.1. Plant Material and Extraction. A total of $500 \mathrm{~g}$ of dried fruits of $L$. barbarum were placed in boiling $3 \mathrm{~L}$ water $\left(100^{\circ} \mathrm{C}\right)$ for $4 \mathrm{~h}$ according to a traditional method described as in the previous study [21]. After filtration, using Whatman no. 3 filter paper, the aqueous extract of $L$. barbarum was lyophilized. For the ethanol extracts, $500 \mathrm{~g}$ of dried fruits was placed in $3 \mathrm{~L}$ of ethanol for $3 \mathrm{~h}$ at $70^{\circ} \mathrm{C}$. The solution was filtrated with Whatman no. 3 filter paper and then evaporated at $35^{\circ} \mathrm{C}$ with reduced pressure.

2.2. Cell Culture. Arising retinal pigment epithelia cell line-19 (ARPE-19), a monolayer of polarized epithelial cells located between the sensory retina and choriocapillaris, is differentiated and mitotically inactive under normal physiological conditions. The ARPE-19 (No. 60,383), obtained from the Bioresource Collection and Research Center (BCRC, Hsinchu, Taiwan), was grown in DMEM medium (Dulbecco's Modified Eagle's Medium, Invitrogen Corporation, Carlsbad, CA, USA) supplemented with $10 \%$ (v/v) fetal bovine serum, $100 \mathrm{units} / \mathrm{mL}$ penicillin, and $100 \mu \mathrm{g} / \mathrm{mL}$ streptomycin in an incubator with $5 \% \mathrm{CO}_{2}$ at $37^{\circ} \mathrm{C}$. Cells were pretreated with $L$. barbarum extracts (from 0 to $200 \mu \mathrm{g} / \mathrm{mL}$ ) for $2 \mathrm{~h}$; then, cells were exposed to $50 \mathrm{~mJ} / \mathrm{cm}^{2}$ of UVB cultured for $24 \mathrm{~h}$. The experiment of different exposing dose of UVB was performed in triplicate and repeated three times to ensure reproducibility.

2.3. Assessment of Cell Viability. The cell viability was assessed using a colorimetric tetrazolium 3-[4, 5-dimethylthiazol-2-yl]-2, 5 diphenyl tetrazolium bromide (MTT) assay. Briefly, $1 \times 10^{4}$ cells were seeded into a 96-well plate, and the cells were treated with different exposing doses of UVB (from 0 to $60 \mathrm{~mJ} / \mathrm{cm}^{2}$ ) for indicated periods (24 and $48 \mathrm{hr}$, respectively). The final concentration of MTT in each well was $0.5 \mathrm{mg} / \mathrm{mL}$, and the cells were further incubated. Afterward, the media containing MTT were removed, and the crystal formazan was dissolved entirely with Dimethyl sulfoxide (DMSO). The absorption length of light was measured at $570 \mathrm{~nm}$ using a microplate reader (Thermo, Massachusetts, USA), and the relative cell viability was presented as the percentage of absorbance values in treated cells to that of control cells.

2.4. Assessment of Cell Cycle Distribution. The assay of flow cytometer-based propidium iodide (PI) staining was used for detecting cell cycle distribution as described previously [22]. Briefly, ARPE-19 cells were pretreated with LBA and LBE for $2 \mathrm{~h}$; then, the cells were irradiated with $50 \mathrm{~mJ} / \mathrm{cm}^{2}$ UVB for $24 \mathrm{hr}$. Afterward, trypsin-suspended cells were washed and ethanol-fixed. After centrifugation, the cells were stained with $10 \mu \mathrm{g} / \mathrm{mL}$ PI (Sigma, St. Louis, MO) and $10 \mu \mathrm{g} /$ $\mathrm{mL}$ RNase $\mathrm{A}$ at room temperature in the dark. The PIstained cells were further analyzed by FACScan, a flow cytometer (Becton-Dickinson, Mansfield, MA), and WinMDI/ PC-freeware V2.9 (Joseph Trotter, La Jolla, CA, USA).

2.5. Assessment of Mitochondrial Membrane Potential $(\Delta \Psi \mathrm{m})$. The changes in the mitochondrial membrane potential $(\Delta \Psi \mathrm{m})$ were assessed using a mitochondrial permeable lipophilic cationic dye 5,5,6,6-Tetrachloro-1,1,3,3-tetraethylbenzimidazolylcarbocyanine iodide (JC-1). In healthy cells, JC-1 accumulates in the mitochondria and emits red fluorescence $(560 \mathrm{~nm})$; however, in mitochondrial cells with changed membrane potential, the JC-1 accumulates in the cytoplasm and emits fluorescence $(530 \mathrm{~nm})$. ARPE-19 cells were pretreated with $\mathrm{LBA}$ and $\mathrm{LBE}$ and incubated with $10 \mathrm{mg} / \mathrm{mL} \mathrm{JC}-1$ at $37^{\circ} \mathrm{C}$ in the dark. Cells were washed twice with serum-free medium and detected using a fluorescence microscope (Olympus IX71 CTS).

2.6. FITC-Annexin VIPI Apoptosis Assay. The assessment of apoptotic cells was performed according to previous work [22]. Briefly, cells were pretreated with LB extracts $2 \mathrm{hr}$, respectively, prior to UVB irradiation for $24 \mathrm{hr}$. The changes of early and late apoptosis were determined using an Annexin-V-Fluorescein isothiocyanate (FITC)/PI Apoptosis Detection kit (BioVision, CA 94043, USA). Briefly, cells were resuspended in binding buffer then incubated in the dark with FITC-labeled Annexin V and propidium iodide for $15 \mathrm{~min}$ at room temperature; finally, the samples were diluted with phosphate-buffered saline (PBS). Flow cytometry was carried out on a FACScan instrument (FACS Calibur; Becton Dickinson, Mountain View, CA, USA), and data were 
processed with WinMDI/PC-software V2.9 (written by Joseph Trotter, Scripps Research Institute, La Jolla, CA, USA). Cells labeled with annexin conjugated with the FITC fluorescence were recognized as apoptotic populations.

2.7. Determination of Intracellular ROS. We measured the changes in intracellular ROS according to the previous work with minor modifications [23]. $5 \times 10^{5}$ cells were seeded in a six-well plate in triplicate. The cells were pretreated with or without LBA and LBE $2 \mathrm{hr}$ prior to the UVB irradiation. After $12 \mathrm{hr}$, the cells were washed twice with PBS, collected, and then further incubated with $10 \mu \mathrm{M}$ dichloro-dihydrofluorescein diacetate probe (DCFH-DA, Molecular Probes Inc., Eugene, OR, USA) at $37^{\circ} \mathrm{C}$ for $30 \mathrm{~min}$. The fluorescence intensity of DCFH was quantified by flow cytometry (the length of excitation is $485 \mathrm{~nm}$, and the length of emission is $525 \mathrm{~nm}$ ). The results were presented as the percentage of the control cells (100\%).

2.8. Assessment of DNA Damage. Briefly, cells were pretreated with LB extracts $2 \mathrm{hr}$, respectively, prior to UVB irradiation. Afterward, cells were harvested and fixed with $70 \%$ ethanol at $-20^{\circ} \mathrm{C}$ overnight; then, the cells were washed twice with BSA-T-PBS solution (1\% BSA and $0.2 \%$ Triton X-100 in PBS). The cells were then incubated with $0.2 \mu \mathrm{g} / \mathrm{mL}$ antibodies against phosphorylated-Ser ${ }^{139} \mathrm{H} 2 \mathrm{AX}(\gamma \mathrm{H} 2 \mathrm{AX})$, and the secondary antibody was subsequently conjugated with Alexa Fluor 488 (Jackson Laboratory, Bar Harbor, Marine, USA). The intensity of fluorescence was measured by flow cytometry (FACSCalibur, Becton-Dickinson). The results were quantified using the software Cell Quest (Becton-Dickinson).

2.9. Microarray Analysis. RNA molecules were isolated using MirVana Total RNA Isolation Kit (Applied Biosystems, Foster City, CA, USA) according to the instructions of the manufacturer. The microarray and the data analysis were performed by Welgene Biotech (Taipei, Taiwan) using the SurePrint G3 GE $8 \times 60 \mathrm{~K}$ Microarray, $8 \times 60 \mathrm{~K}$, AMADID 028005 (Agilent Technologies, USA [24]). The arrays were scanned with G2505C Microarray Scanner (Agilent). The information of probes on the arrays was extracted from the image data using Feature extraction 10.5.1.1 (Agilent) for quantifying signal and the intensity of background.

2.10. Ingenuity Pathway Analysis. The molecular functions of the unique gene analysis of the UVB-induced genes were analyzed using the software Ingenuity Pathway Analysis ${ }^{\circledR}$ (IPA, Ingenuity Systems, Redwood City, California, USA). The changed genes which met the criteria and were correlated with the biological functions of the Ingenuity Pathways Knowledge Base (Ingenuity Systems) were included.

2.11. Statistical Analysis. All experiments were conducted in triplicate, and the data were represented as mean \pm SD. The data were subjected to an analysis of variance (ANOVA) and Duncan's multiple range tests. $p<0.05$ was considered significant.

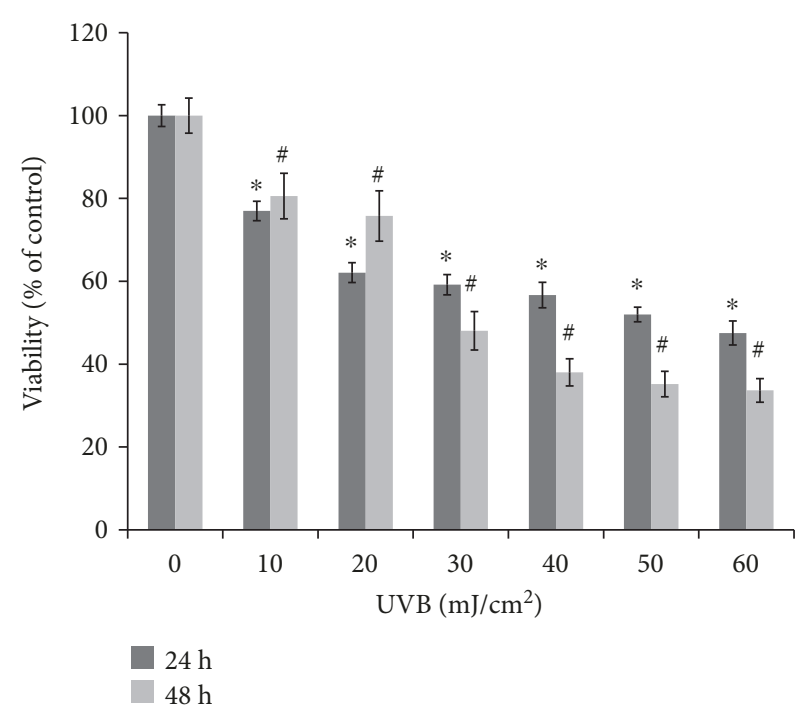

FIgURE 1: The viability of UVB irradiation on growth of ARPE-19 cells. The cells were exposed to the irradiation of UVB at indicated doses and then incubated further for $24 \mathrm{hr}$ and $48 \mathrm{hr}$, respectively. The viability of cells was determined by MTT assay. The results are expressed as mean \pm standard deviation (SD) $(n=3)$. The $\left(^{*}\right)$ asterisk and $\left(^{\#}\right)$ hash symbols indicate $p<0.05$ vs. cells without UVB irradiation for $24 \mathrm{hr}$ and $48 \mathrm{hr}$, respectively.

\section{Results}

3.1. UVB-Induced Cell Death in Retinal Pigment Epithelial Cells. ARPE-19 cells were exposed to UVB light with indicated doses of UVB (from 0 to $60 \mathrm{~mJ} / \mathrm{cm}^{2}$, respectively) for $24 \mathrm{hr}$, and the cell viabilities were $100 \pm 2.61 \%$, $76.97 \pm 2.35 \%, 62.08 \pm 2.40 \%, 59.17 \pm 2.43 \%, 56.68 \pm 3.08 \%$, $51.98 \pm 1.78 \%$, and $47.52 \pm 2.92 \%$. At $48 \mathrm{hr}$, viabilities were $100 \pm 4.22 \%, \quad 80.57 \pm 4.48 \%, \quad 75.77 \pm 6.09 \%, \quad 48.06 \pm 4.68 \%$, $38.02 \pm 3.27 \%, 35.20 \pm 3.08 \%$, and $33.66 \pm 2.86 \%$ (Figure 1). The results showed that the irradiation of $50 \mathrm{~mJ} / \mathrm{cm}^{2} \mathrm{UVB}$ significantly induced cell death of RPE cells.

3.2. L. barbarum Extracts Reduced UVB-Induced Cell Death in Retinal Pigment Epithelial Cells. To evaluate whether LBA and LBE protected ARPE-19 cells against UVBinduced cell death, we detected the viability of ARPE-19 cells after UVB $\left(50 \mathrm{~mJ} / \mathrm{cm}^{2}\right)$ incubation for $24 \mathrm{hr}$ and $48 \mathrm{hr}$, with or without LBA and LBE pretreatment in 25 and $50(\mu \mathrm{g} /$ $\mathrm{mL}$ ). As shown in Figure 2, the viability of cells was decreased to $44.51 \pm 2.38 \%$ after being exposed to UVB $\left(50 \mathrm{~mJ} / \mathrm{cm}^{2}\right)$ for $24 \mathrm{hr}$; LBA and LBE pretreatments with a variety of concentrations from $25 \mu \mathrm{g} / \mathrm{mL}$ to $50 \mu \mathrm{g} / \mathrm{mL}$ for $48 \mathrm{hr}$ prevented the loss of cell viability. Finally, $50 \mu \mathrm{g} / \mathrm{mL}$ of both LBA and LBE increased the cell variety from 44.51 $\pm 2.38 \%$ to $53.54 \pm 2.35 \%$ and from $44.51 \pm 2.38 \%$ to $57.96 \pm 6.50 \%$, respectively.

3.3. $L B A$ and LBE Reduce Endogenous ROS Level after Irradiated ARPE-19. As shown in Figure 2, the pretreatments of LBA and LBE rescue the viability of ARPE-19 cells following the irradiation of UVB. Under normal conditions, reactive oxygen species (ROS) could act as a second 


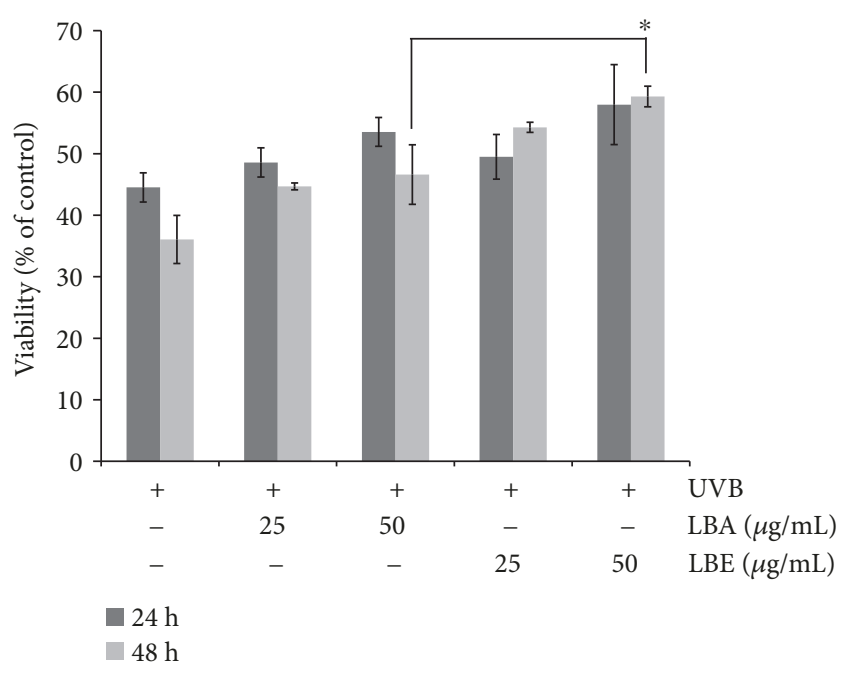

FIGURE 2: L. barbarum extracts rescue the viability of UVB-treated cells in an appropriate concentration. ARPE-19 cells were pretreated with either LBA or LBE for $2 \mathrm{hr}$ before being exposed to UVB irradiation. The cell viability was determined by MTT assay $24 \mathrm{hr}$ and $48 \mathrm{hr}$ after UVB irradiation $\left(50 \mathrm{~mJ} / \mathrm{cm}^{2}\right)$. The control group was the UVB-irradiated cells without L. barbarum extracts. The results are expressed as a percentage of control and are represented by mean $\pm \mathrm{SD}(n=3)$. The asterisk indicates $p<$ 0.05 vs. UVB-exposed cells without LBA and LBE pretreatments.

messenger in cell signaling and regulates various biological functions [25-27]. However, excess ROS production could inhibit proliferation of cells and cause cell death [26-29]. A high level of endogenous ROS is highly correlated with the pathophysiology of retinal degeneration diseases including AMD. After exposure to UVB, levels of ROS will reach 29.4 $\pm 5.4 \%$, compared to pretreatment with LBA and LBE in a high dose of $50(\mu \mathrm{g} / \mathrm{mL})$ then down to $5.9 \pm 0.3 \%$ and 4.7 $\pm 0.2 \%$, respectively. As shown in Figure 3, LBA and LBE reduced the levels of endogenous ROS in human ARPE-19 cells after the irradiation of UVB $(p<0.05)$.

3.4. LBA and LBE Significantly Reduced UVB-Induced Apoptosis of ARPE-19. To determine whether LBA and LBE mitigated cell apoptosis in UVB-irradiated ARPE-19 cells, the cytometer-based Annexin V/PI dual staining assay was conducted. ARPE-19 cells were cultured with 0, 25, and $50 \mu \mathrm{g} / \mathrm{mL}$ of LBA and LBE for $24 \mathrm{hr}$ before being irradiated with UVB $50 \mathrm{~mJ} / \mathrm{cm}^{2}$ for $24 \mathrm{hr}$. Data are represented as (mean $\pm \mathrm{SD}$ ) of five individual experiments, with $p<0.05$ compared with control. Following UVB-induced apoptosis of ARPE-19 cells, incubation of two treatments for $24 \mathrm{hr}$ demonstrated levels of apoptotic cells decreased from 29.5 $\pm 3.4 \%$ to $15.7 \pm 5.1 \%$ and $9.3 \pm 2.3 \%$ by LBA and down to $14.7 \pm 5.1 \%$ and $9.4 \pm 1.7 \%$ by LBE, respectively. As shown in Figure 4, the results showed that both treatments protect apoptosis in the ARPE-19 cells, suggesting the protective effects of LBA and LBE on ARPE-19 cell.

3.5. L. barbarum Extracts Attenuate UVB-Induced Loss of Mitochondrial Membrane Potential. Mitochondria-mediated signaling is mainly responsible for apoptosis; we further determined whether LB extract protects UVB-induced apoptosis through the regulation of mitochondrial signaling. The JC-1 fluorescence dye was used for detecting the loss of mitochondrial membrane potential (MMP), a marker of mitochondrial-mediated apoptosis [30]; therefore, we assessed the MMP membrane potential $(\Delta \Psi \mathrm{m})$ in UVBirradiated cells using JC-1 staining. As shown in Figure 5, the results show that $L$. barbarum extract pretreatment had strong intensity of red fluorescence (J-aggregation) and weak intensity of green fluorescence (JC-1 monomer) compared to UVB irradiation alone, indicating that both $L$. barbarum extracts LBA and LBE prevent the loss of MMP in UVBirradiated cells.

3.6. LBA and LBE Protected UVB-Induced DNA Damage of ARPE-19 Cells. $\gamma \mathrm{H} 2 \mathrm{AX}$, a phosphorylated histone variant $\mathrm{H} 2 \mathrm{AX}$ at site $\mathrm{Ser}^{139}$, is a marker of DNA damage [31]. The assessment of $\gamma \mathrm{H} 2 \mathrm{AX}$ is widely used for detecting DNA damage. As shown in Figure 6, the protective ability of both LBA and LBE pretreated with various concentrations at 25 and $50 \mu \mathrm{g} / \mathrm{mL}$ shows $24.6 \pm 2.1 \%$ of UVB-irradiated, $8.7 \pm 0.4 \%$ and $6.6 \pm 0.9 \%$ of LBA, and $7.8 \pm 0.6 \%$ and $6.6 \pm 0.4 \%$ of LBE significantly attenuated the activation of $\gamma \mathrm{H} 2 \mathrm{AX}$ in a dose-responsive manner, suggesting a protective role of both LBA and LBE in UVB-induced apoptosis of human ARPE-19 cells.

\section{Discussion}

Chronic photooxidative stress from the environment could cause various damages including the integrity of the membrane, increased ROS, DNA damage, and cell death of RPE. Dysfunction and degeneration of RPE cells are crucially involved in the pathogenesis of AMD or other RPE degeneration-associated diseases [32, 33]. The apoptotic death of RPE cells, followed by photoreceptor cell death, is thought to mainly contribute to the pathogenesis of the dry form of AMD [33]. The progression of AMD pathogenesis is highly correlated with various oxidative stresses and could be prevented or delayed by supplying vitamin $C$ or other antioxidants [34, 35]. L. barbarum (wolfberry) has been used as a traditional antiaging herb in Chinese pharmacopeia over a long history [36]. LBA, the primary active ingredient of lycium barbarum, isolated from the aqueous extracts of lycium barbarum, has multibioactivity properties on modulating cellular physiology, and LBA could exert protective effects on hepatocytes and neurons of the eye [37-40]. However, little is known regarding ethanol extracts of $\mathrm{LB}$.

To confirm whether LB extracts LBA and LBE could protect ARPE-19 cells against UVB-induced cell damage, we first examine the viability of ARPE- 19 cells after the irradiation of UVB. Our results showed that the pretreatments of both LBA and LBE significantly mitigated the proliferation of ARPE-19 cells. Under normal conditions, reactive oxygen species (ROS) could act as a second messenger in cell signaling and regulates various biological functions [25-27]; however, a high level of endogenous ROS is highly correlated with the pathophysiology of retinal degeneration diseases including 


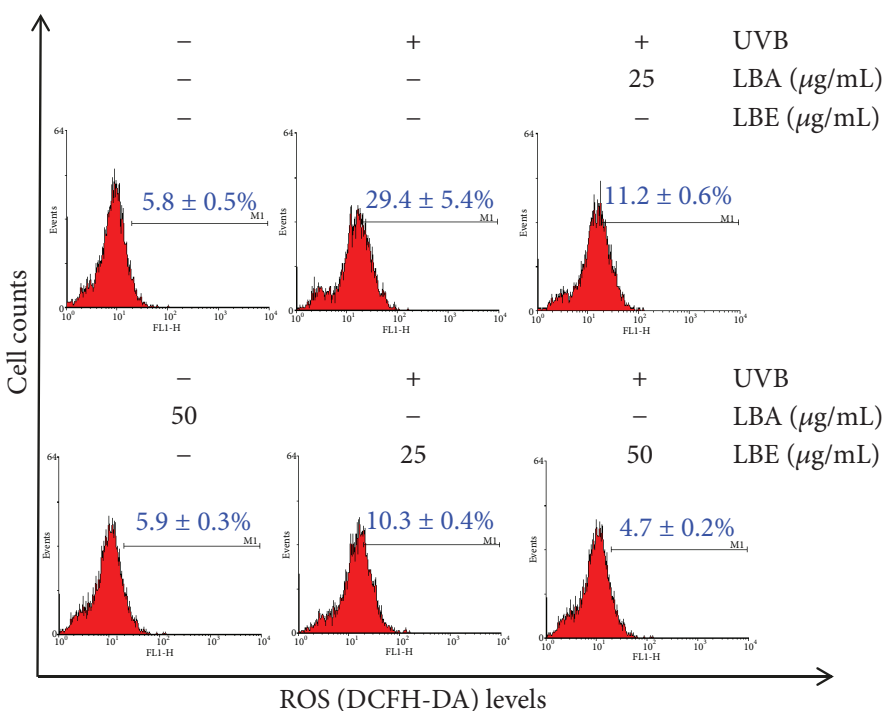

(a)

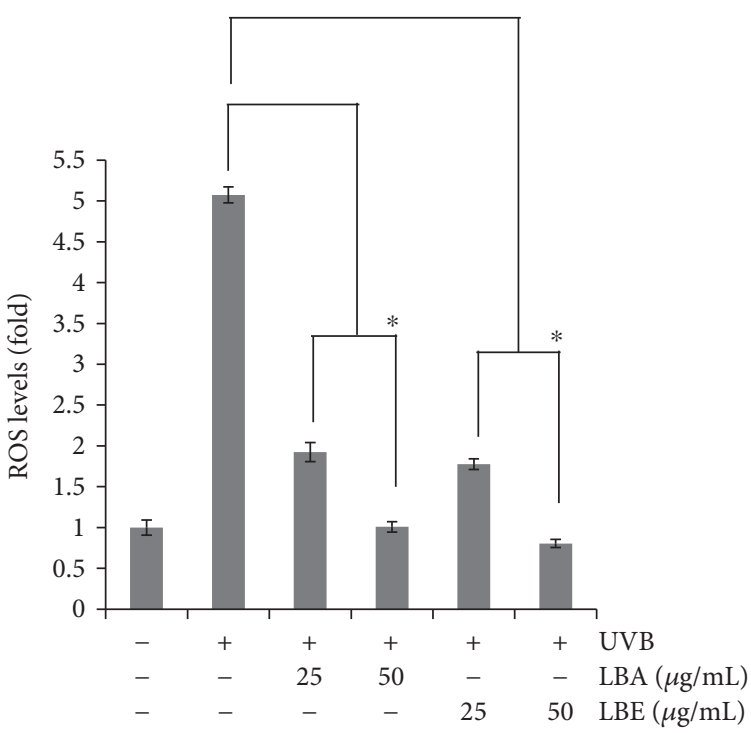

(b)

FIGURE 3: Effect of L. barbarum extracts on reactive oxygen species (ROS) production of ARPE19 cells after UVB irradiation exposure. (a) ARPE-19 cells pretreated with PBS or L. barbarum extracts LBA and LBE 25 and $50 \mu \mathrm{g} / \mathrm{mL}$ for $2 \mathrm{hr}$. After being exposed to $50 \mathrm{~mJ} / \mathrm{cm}^{2}$ UVB irradiation, cells were harvested and subjected to a flow cytometer-based DCFDA staining assay, which is oxidized by ROS to the high fluorescence of DCF for detecting the changes of $\mathrm{H}_{2} \mathrm{O}_{2}$ in cells. (b) The quantitative analysis of (a). The asterisk symbols indicate $p<$ 0.05 vs. UVB-irradiated cells without LBA or LBE pretreatments.

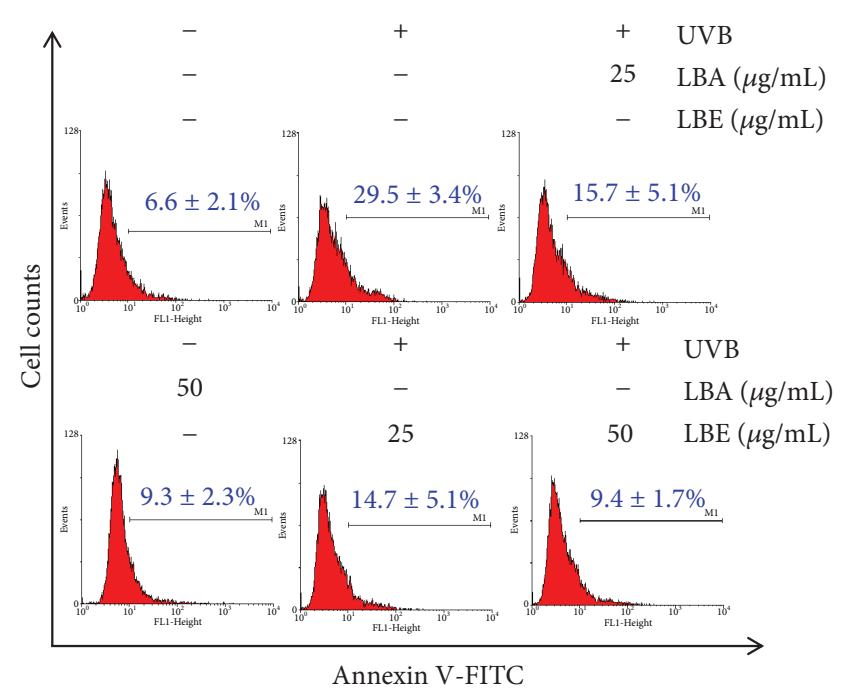

(a)

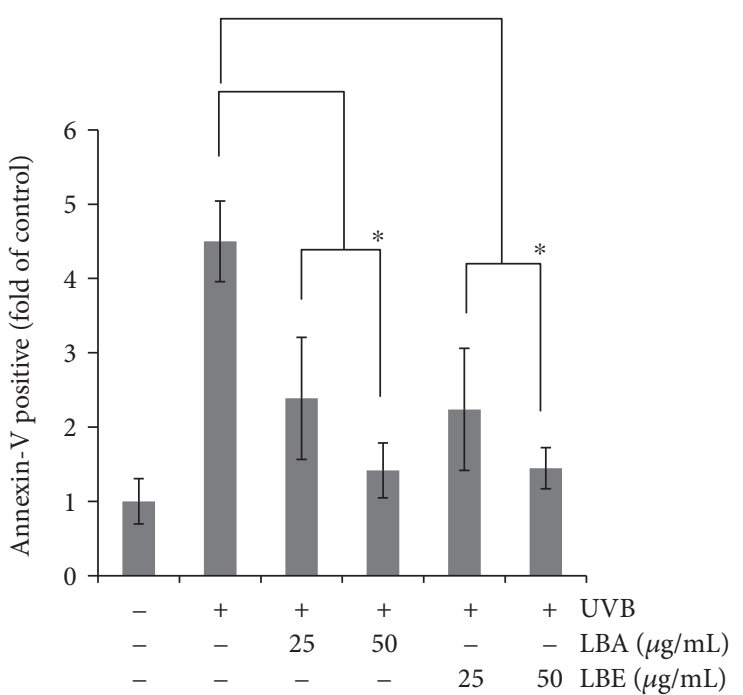

(b)

FIgURe 4: Pretreatment with L. barbarum extracts rescues UVB-induced apoptosis of retinal pigment epithelial cells. (a) ARPE-19 cell was pretreated with vehicle control or L. barbarum extracts LBA and LBE for $2 \mathrm{hr}$, respectively, prior to the irradiation of $50 \mathrm{~mJ} / \mathrm{cm}^{2} \mathrm{UVB}$. Afterward, cells were harvested and assessed using a flow cytometer-based Annexin V staining. Results are represented as mean \pm SD. (b) The quantitative analysis of (a). The asterisk indicates $p<0.05 v s$. UVB-irradiated cells without LBA and LBE pretreatments.

AMD. Here, we demonstrated that both aqueous and ethanol extracts of $L$. barbarum could enhance antioxidant activities and attenuate the levels of endogenous ROS in ARPE-19 cells. Furthermore, both aqueous and ethanol extracts of $L$. barbarum have potent antioxidant activities and rescue cells from UVB-induced apoptosis. Moreover, ethanol extracts of $L$. barbarum display stronger antioxidant effects than the aqueous extract of L. barbarum. For bioactive constituents, $L$. barbarum is rich in antioxidants, including hydrophilic polysaccharides [41] and the hydrophobic flavonoids carotenoid and riboflavin [42]. Despite polysaccharide fractions, LBP has been shown to have antioxidant activity, and a previous study revealed that crude polysaccharide extracts exhibited stronger antioxidant activity than purified polysaccharide fractions (LBP) because antioxidants such as carotenoids, riboflavin, ascorbic acid, thiamine, and nicotinic acid are more abundant in crude extracts. In our study, the results showed that both $\mathrm{LBA}$ and $\mathrm{LBE}$ reduced the level of 


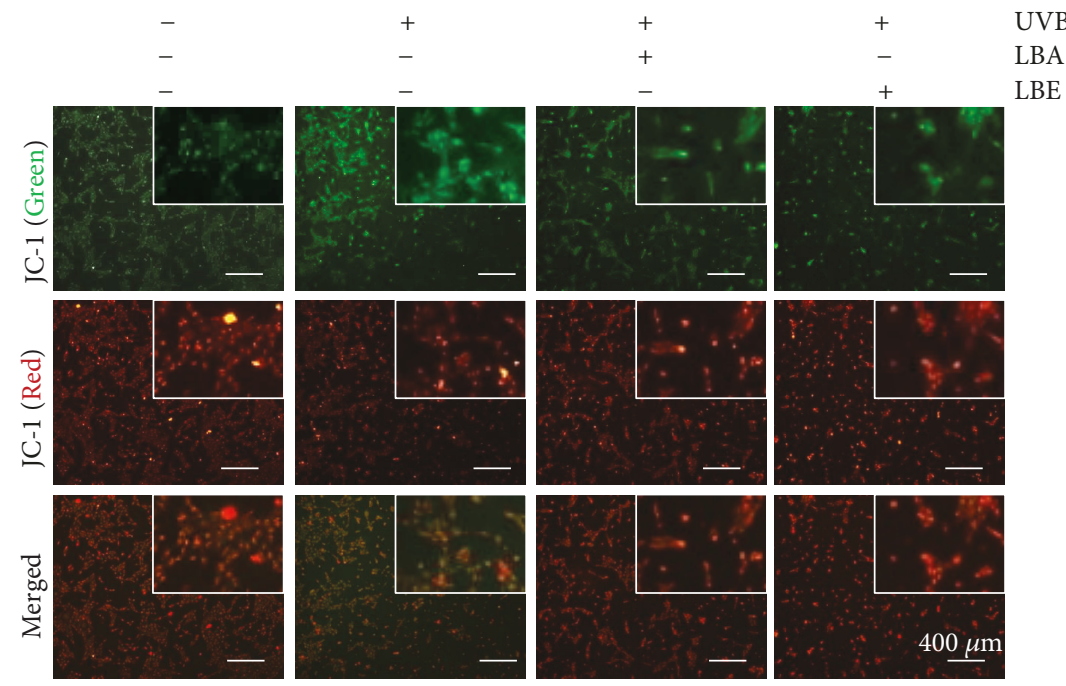

FIgURE 5: The effect of L. barbarum extracts on the UVB-induced loss of mitochondrial membrane potential (MMP). ARPE-19 cells pretreated with $50 \mu \mathrm{g} / \mathrm{mL} \mathrm{LBA}$ or LBE, respectively, prior to the irradiation of $50 \mathrm{~mJ} / \mathrm{cm}^{2}$ UVB light. Afterward, the changes of MMP $(\Delta \Psi \mathrm{m})$ were detected by a fluorescence microscope-based JC-1 staining assay. The wavelengths of emission are $580 \mathrm{~nm}$ (red, upper panels) and $530 \mathrm{~nm}$ (green, lower panels). Scale bars: $400 \mu \mathrm{m}$.

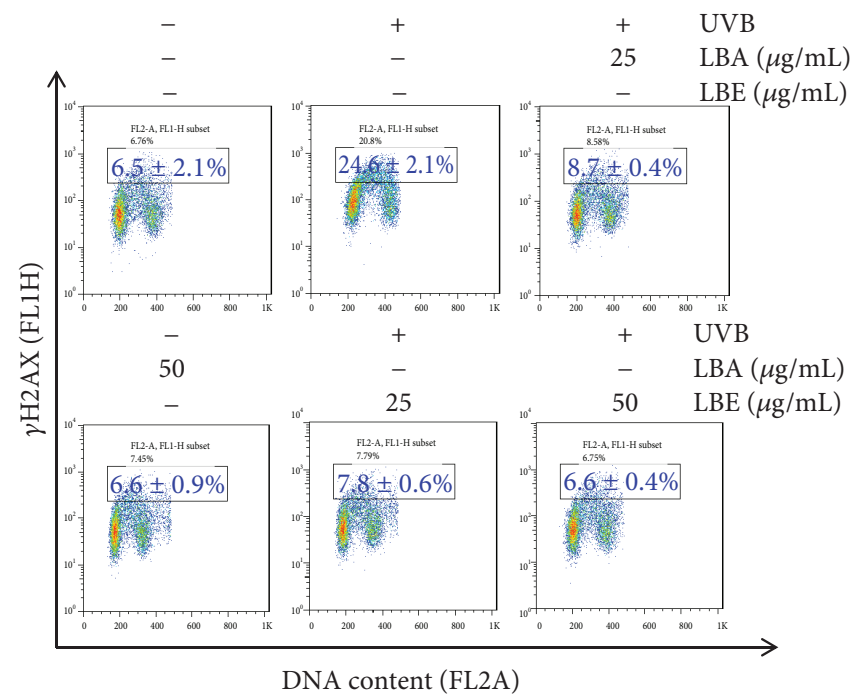

(a)

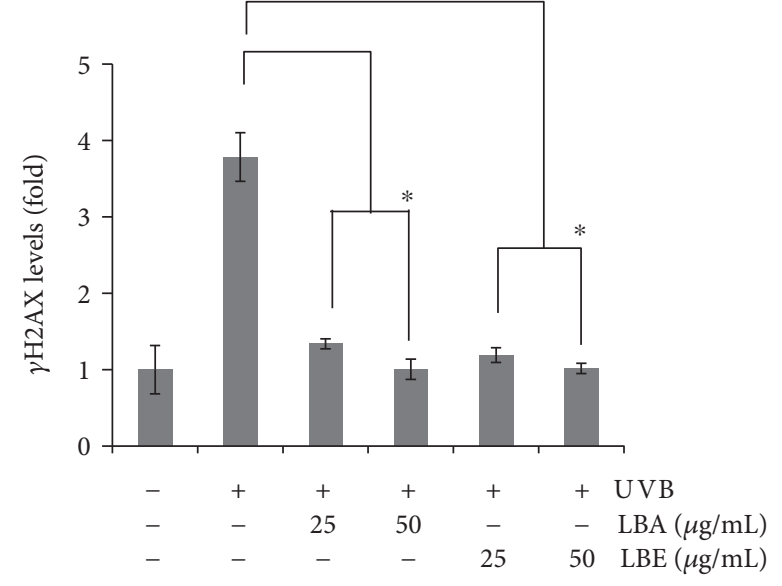

(b)

FIGURE 6: The protective effect of LB extracts on UVB-induced DNA damage of ARPE-19 cells. (a) ARPE-19 cells pretreated with LBA and $\mathrm{LBE} 25$ and $50 \mu \mathrm{g} / \mathrm{mL}$ for $2 \mathrm{hr}$ prior to the exposure to $50 \mathrm{~mJ} / \mathrm{cm}^{2}$ UVB irradiation, cells were harvested and subjected to the flow cytometerbased $\gamma \mathrm{H} 2 \mathrm{AX}$ immunostaining assay and repeated in three independent experiments. (b) The quantitative analyses of $\gamma \mathrm{H} 2 \mathrm{AX}$ level in ARPE19 cells $(n=3)$. The asterisk indicates $p<0.05 v$ s. UVB-exposed cells without the pretreatment of LB extracts.

ROS in human ARPE-19 cells after UVB irradiation. Moreover, the JC-1 staining for detecting the loss of mitochondrial membrane potential (MMP) as a marker of mitochondrialmediated apoptosis was conducted, and the results showed that the pretreatment of both LB extracts prevented the loss of MMP following UVB irradiation.

Therefore, we further determined whether LBA and LBE occluded cell apoptosis under UVB-irradiated ARPE-19 cells using a cytometer-based Annexin V/PI double staining assay. Consistently, our results showed that UVB-induced apoptosis of ARPE-19 cell at $24 \mathrm{hr}$; however, the percentages of UVB-induced apoptotic cells were decreased with both LB extract pretreatments. Both extracts exerted protective effects on UVB-induced apoptosis in an ARPE-19 cell line. It is well known that irradiation of UVB or visible light causes photochemical lesions or other damages through the induction of DNA damage [43]; therefore, examination of whether LB extracts could protect ARPE-19 cells from DNA damage using the assessment of $\gamma \mathrm{H} 2 \mathrm{AX}$, a marker of DNA damage [31], is desirable. 
Our results showed that the pretreatments of both LBE and LBA significantly attenuated the activation of $\gamma \mathrm{H} 2 \mathrm{AX}$ in a dose-responsive manner, suggesting a protective role of LB extracts in UVB-induced DNA damage of human ARPE-19 cells. Because of the great benefits of L. barbarum, many studies have been conducted extensively on the preventive effects of LB extracts against eye diseases [44-46]. For example, the work of Li et al. suggested that LBP is neuroprotective and could delay secondary degeneration of retinal ganglion cells (RGCs), which might be associated with the downregulation of oxidative stress and the MAPK JNK/c-Jun pathway in retinal tissue [46]. Furthermore, the work of Liu et al. demonstrated that the treatment of LBP not only improves morphology and function of retinal tissue in $\mathrm{rd} 1$ mice, an in vivo photoreceptor degenerating model of retinitis pigmentosa, but also delays the functional degeneration of RGCs [45]. However, little is known regarding the bioactivity and mechanism of L. barbarum against DNA damage; consequently, our study is the first to reveal L. barbarum extracts as protective agents for UVB-induced DNA damage.

Previously, Lin et al.'s work analyzed the interrelationship between Lycium barbarum and gene expression in mouse spleen using oligo-microarray, and their result showed that three genes, $\mathrm{Bcl}-2, \mathrm{NF} \kappa \mathrm{B}$, and TNF, were upregulated whereas two proapoptotic genes (apoptotic proteaseactivating factor-1 (apaf-1) and caspase-3) were downregulated by the treatment of Lycium barbarum [47]. Given the superior cytoprotection on UVB irradiation-induced growth arrest by ethanol extract LBE, we further investigated the mechanism using human global gene expression profiles of RNA isolated from ARPE-19 cells pretreated with $L$. barbarum extracts LBE or LBA prior to the irradiation of UVB analyzed by a cDNA microarray at $24 \mathrm{hr}$. We identified that a total of 403 genes in LBE-treated cells and a total of 558 genes in LBA-treated cells were changed, and 308 genes might be involved in the signaling pathways associated with the protective effect of $L$. barbarum extracts using analysis by IPA bioinformatics software (Figure 7(a)). The analysis of IPA further suggested that three signaling pathways of the top-level functional annotation categories of genes including PPAR, Integrin survival signaling, and Toll-like receptor (TLR) signaling pathways were affected by the pretreatment of both L. barbarum extracts LBE and LBA (Figures 7(b) and 7(c)).

Peroxisome proliferator-activated receptors (PPARs) are important nuclear transcription factors for oxidative defense system in eukaryotic cells. The PPAR family has at least three members including $\operatorname{PPAR} \alpha, \operatorname{PPAR} \beta / \delta$, and $\operatorname{PPAR} \gamma$ [48]. For example, PPAR $\gamma$ has been shown to have an antioxidant function through transcriptional regulating a number of antioxidation-associated gene catalase (CAT), glutathione peroxidase (GPX-3), heme oxygenase-1 (HO-1), and manganese superoxide dismutase (MnSOD) [49].

Integrins are transmembrane proteins and the heterodimerization of integrin receptors have been shown to regulate cell survival, differentiation, and migration of metazoa through communicating signals via the plasma membrane [50]. Neuronal survival is exhibited by olfactory ensheathing cell, a type of glia that supports axon outgrowth olfactory system through integrin/milk fat globule-EGF factor 8 ((MFG-E8) a secreted glycoprotein) signaling pathway [51]. Moreover, a recent study demonstrated that the sensory axons of the spinal cord can regenerate by expressing tenascin-binding $\alpha 9$-integrin together with kindlin-1, the integrin activator [52].

Toll-like receptors (TLRs) are single and noncatalytic receptors with membrane-spanning domains and the TLRs can recognize microbial pathogen and initiate signal transduction pathways of innate immunity [53]. Beyond the role of TLRs in activating innate immunity, TLR seems to play a critical role in neuron survival [54-57]. Patel and Hackam's work suggested that the oxidative stress-activated TLR3 triggers neuron protection rather than pathogenic signaling in the retina tissue of mice [58]. Bsibsi et al.'s work showed that inflammation-induced TLR-3 activation triggers a neuroprotective response rather than a proinflammatory response in human astrocytes [59]. Furthermore, Jeong et al.'s work showed that polyinosinic poly-cytidylic acid- (poly(I:C)-) induced activation of TLR3 might favor the survival of microglia after cerebral ischemia, suggesting the neuroprotective role of TLR3 [60]. Controversially, the activation of TLR might also create a degenerative effect in neuron cells; for example, Chintala et al.'s work showed that poly(I:C)induced TLR3 activation upregulated the protein level of MAPK JNK3 and promoted the degeneration of RGCs in mouse eye [61]. Similarly, Gao et al.'s work showed that poly(I:C)-induced TLR3 evoked an inflammatory response and cell death both in murine photoreceptor 661W cells and an in vivo model [62]. Therefore, the role of TLR in prosurvival or pro-cell death of neuron cells may depend on the types [55] of stimuli, the level [60] of stimuli, and the downstream of TLR signaling [58].

In the results of microarray analysis combining the IPA bioinformatics approach, the activation level of the TLR pathway is higher in LBE pretreatment than that in LBA pretreatment (Figures $7(\mathrm{~b})$ and $7(\mathrm{c})$ ). Given the pivotal role of the TLR pathway in cell proliferation and cell survival [63], it is worth further investigating the three signaling pathways, especially the TLR pathway in LB extract-mediated cytoprotection in human retinal pigment epithelial cells.

4.1. $L B A$ and LBE Rescue UVB-Induced $G_{2}$-Arrest after Irradiated ARPE-19. In the study, $50 \mathrm{~mJ} / \mathrm{cm}^{2}$ of UVB irradiation significantly caused the accumulation of cell cycle $\mathrm{G}_{2} /$ $M$ population in human ARPE-19 cells. Interestingly, Chou et al.'s work showed that 10 to $30 \mathrm{~mJ} / \mathrm{cm}^{2}$ UVB caused Sarrest in ARPE-19 cells [64]; we suggest that different doses of UVB irradiation might result in the discrepancy in the arrest of cell cycle $S$ and $G_{2} / M$ phases. Furthermore, the pretreatment of both LBA and LBE rescues UVB irradiationinduced $\mathrm{G}_{2} / \mathrm{M}$-arrest in ARPE-19 (Figure S1).

\section{Conclusions}

We demonstrated that both aqueous and ethanol extracts of L. barbarum exhibit antioxidant activities and prevent UVB irradiation-induced DNA damage and apoptosis of ARPE cells. Interestingly, ethanol extracts of $L$. barbarum exert 

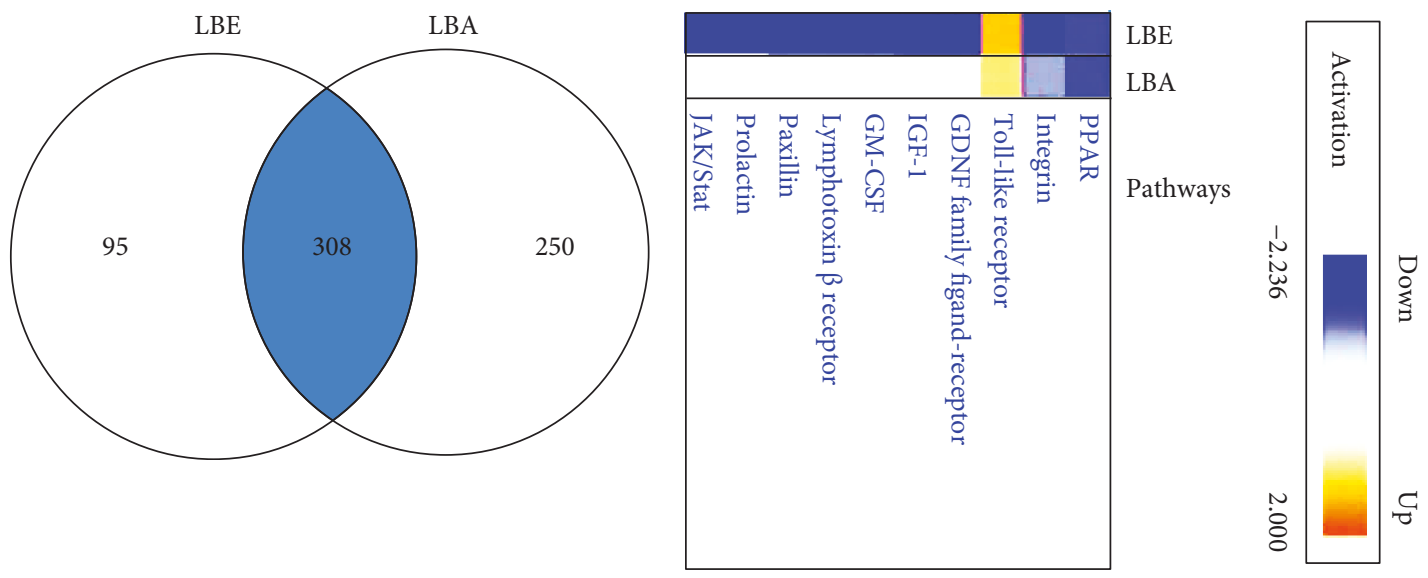

(a)

(b)

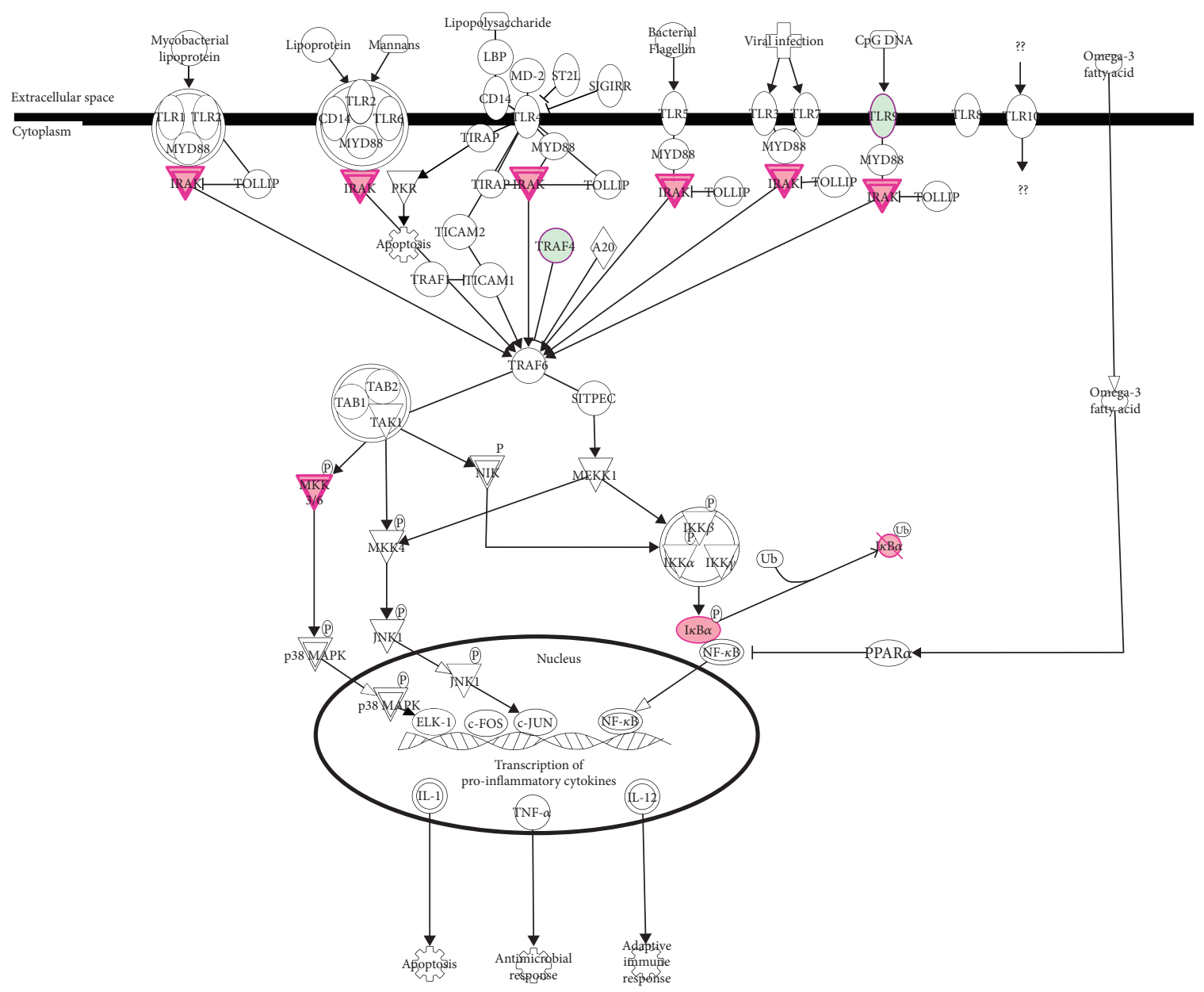

(c)

FIgURE 7: Activation of genes involved in L. barbarum extract-mediated protective effect on UVB irradiation. The human global gene expression profiles of RNA were isolated from ARPE-19 cells pretreated with L. barbarum extracts LBE or LBA prior to the irradiation of UVB then analyzed by a cDNA microarray at $24 \mathrm{hr}$. (a) A total of 403 genes in LBE and a total of 558 genes in LBA were changed, and 308 genes might be involved in the signaling pathways associated with the protective effect of L. barbarum extracts using the analysis of IPA bioinformatics software. (b). Top-level functional annotation categories of genes including peroxisome proliferator-activated receptor (PPAR), the nuclear receptor as a transcription factor, Integrin, and Toll-like receptor (TLR) signaling pathways were affected by the pretreatment of both L. barbarum extracts LBE and LBA. Remarkably, the activation level of the TLR pathway is higher in the LBE pretreatment than in the LBA pretreatment. (c) Genes might be involved in the activation of the TLR pathway. A pink color indicates the upregulation of the genes. A green color indicates the downregulation of the genes. 


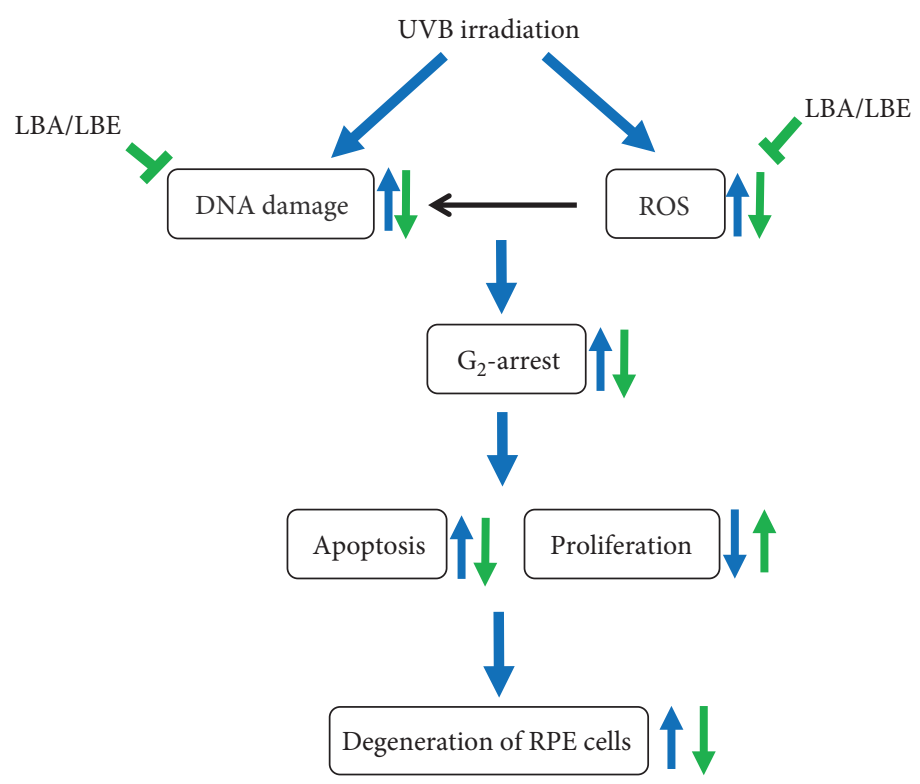

Figure 8: The proposed mechanism of Lycium barbarum extract-mediated protection against UVB-induced damage in human retinal pigment epithelial (RPE) cells. The irradiation of UVB causes the increase of endogenous ROS and the induction of DNA damage, resulting in the damage and degeneration of RPE cells. The extracts of L. barbarum (wolfberry) LBA and LBE exert the potent antioxidant activity and attenuate the DNA damage induced by UVB irradiation in RPE cells, therefore, protecting the RPE cells from UVB-induced cell cycle $\mathrm{G}_{2} / \mathrm{M}$-phase arrest, growth inhibition, and apoptosis, further delaying or attenuating the degeneration of retinal pigment epithelial cells. The blue arrows indicate the impacts of UVB exposure. Green arrows indicate the bioactivities of $L$. barbarum extracts.

stronger antioxidant than aqueous extract, suggesting that polyphenolic components might enhance the antioxidant activities of the ethanol extract of L. barbarum. Based on the results of the present study, we conclude that both aqueous and ethanol extracts of L. barbarum protect ARPE-19 cells from UVB exposure-induced growth and apoptosis through reducing endogenous ROS and DNA damage (Figure 8). This study is the first to depict the cytoprotective activity of $L$. barbarum extracts on cytoprotection in UVBinduced DNA damage in ARPE-19 retinal cells that might be correlated with three signaling pathways including PPAR, Integrin, and TLR. Further investigation on the ethanol extracts of $L$. barbarum will benefit the prevention of retinal degenerative-associated diseases such as AMD in the future.

\section{Data Availability}

The data used to support the findings of this study are available from the corresponding author upon request.

\section{Conflicts of Interest}

The authors declare no conflict of interests.

\section{Acknowledgments}

The study was supported financially by the grants MOST1062320-B-037-012, MOST107-2320-B-037-023, and MOST 107-2311-B-037-001 from the Ministry of Science and Technology, Taiwan; by the grants NSYSU-KMU106-P019 and NSYSU-KMU107-P002 from the National Sun Yat-sen University-KMU Joint Research Project, Taiwan; by the grant from Yuan's General Hospital, Kaohsiung (RG15002); by the grants KMU-SH000151, KMU-M104008, and KMU-TP105A07 from the Kaohsiung Medical University, Taiwan; and by the grants kmhk-105-018 and kmhk-106022 from the Kaohsiung Municipal Hsiaokang Hospital, Taiwan. We are also grateful for the Center for Research Resources and Development (Kaohsiung Medical University) for the instrumental support of IPA analysis, flow cytometer, and confocal microscopy.

\section{Supplementary Materials}

Figure S1: the effect of L. barbarum extract pretreatments on UVB-induced G2-arrest in ARPE-19 cells. ARPE-19 cells were pretreated with $50 \mu \mathrm{g} / \mathrm{mL} \mathrm{L}$. barbarum extracts LBA or LBE, respectively, for $2 \mathrm{hr}$ prior to the irradiation of UVB described in the section of Materials and Methods. (Supplementary Materials)

\section{References}

[1] Macular Photocoagulation Study Group, M. G. Maguire, S. L. Fine et al., "Visual outcome after laser photocoagulation for subfoveal choroidal neovascularization secondary to agerelated macular degeneration: the influence of initial lesion size and initial visual-acuity," Archives of Ophthalmology, vol. 112, no. 4, pp. 480-488, 1994.

[2] S. E. G. Nilsson, S. P. Sundelin, U. Wihlmark, and U. T. Brunk, "Aging of cultured retinal pigment epithelial cells: oxidative reactions, lipofuscin formation and blue light damage," Documenta Ophthalmologica, vol. 106, no. 1, pp. 13-16, 2003. 
[3] T. K. Lim, "Lycium barbarum," in Edible Medicinal and NonMedicinal Plants: Volume 6, Fruits, T. K. Lim, Ed., pp. 240266, Springer Netherlands, Dordrecht, 2013.

[4] A. Capetandes and M. E. Gerritsen, "Simplified methods for consistent and selective culture of bovine retinal endothelial cells and pericytes," Investigative Ophthalmology and Visual Science, vol. 31, no. 9, pp. 1738-1744, 1990.

[5] B. Yue, J. Kawa, I. Chang, S. Sawaguchi, and G. Fishman, "Effects of chondroitin sulfate on cultured human retinal pigment epithelial cells," Cell Biology International Reports, vol. 15, no. 5, pp. 365-376, 1991.

[6] J. Tang and T. S. Kern, "Inflammation in diabetic retinopathy," Progress in Retinal and Eye Research, vol. 30, no. 5, pp. 343358, 2011.

[7] J. M. Sivak and M. E. Fini, "MMPs in the eye: emerging roles for matrix metalloproteinases in ocular physiology," Progress in Retinal and Eye Research, vol. 21, no. 1, pp. 1-14, 2002.

[8] Z. Zheng, H. Chen, G. Ke et al., "Protective effect of perindopril on diabetic retinopathy is associated with decreased vascular endothelial growth factor-to-pigment epithelium-derived factor ratio: involvement of a mitochondria-reactive oxygen species pathway," Diabetes, vol. 58, no. 4, pp. 954-964, 2009.

[9] N. Cheung, P. Mitchell, and T. Y. Wong, "Diabetic retinopathy," Lancet, vol. 376, no. 9735, pp. 124-136, 2010.

[10] C. Dupont, D. Armant, and C. Brenner, "Epigenetics: definition, mechanisms and clinical perspective," Seminars in Reproductive Medicine, vol. 27, no. 5, pp. 351-357, 2009.

[11] E. Miller-Kasprzak and P. P. Jagodzinski, "5-Aza-2'-deoxycytidine increases the expression of anti-angiogenic vascular endothelial growth factor $189 \mathrm{~b}$ variant in human lung microvascular endothelial cells," Biomedicine and Pharmacotherapy, vol. 62, no. 3, pp. 158-163, 2008.

[12] N. Chabane, N. Zayed, H. Afif et al., "Histone deacetylase inhibitors suppress interleukin-1beta-induced nitric oxide and prostaglandin E2 production in human chondrocytes," Osteoarthritis and Cartilage, vol. 16, no. 10, pp. 1267-1274, 2008.

[13] G. Gao, Y. Li, D. Zhang, S. Gee, C. Crosson, and J. X. Ma, "Unbalanced expression of VEGF and PEDF in ischemiainduced retinal neovascularization," FEBS Letters, vol. 489, no. 2-3, pp. 270-276, 2001.

[14] M. Pons and M. E. Marin-Castano, "Nicotine increases the VEGF/PEDF ratio in retinal pigment epithelium: a possible mechanism for $\mathrm{CNV}$ in passive smokers with AMD," Investigative Ophthalmology and Visual Science, vol. 52, no. 6, pp. 3842-3853, 2011.

[15] G. Gao, Y. Li, J. Fant, C. E. Crosson, S. P. Becerra, and J. X. Ma, "Difference in ischemic regulation of vascular endothelial growth factor and pigment epithelium-derived factor in brown Norway and Sprague Dawley rats contributing to different susceptibilities to retinal neovascularization," Diabetes, vol. 51, no. 4, pp. 1218-1225, 2002.

[16] A. S. Bharadwaj, B. Appukuttan, P. A. Wilmarth et al., "Role of the retinal vascular endothelial cell in ocular disease," Progress in Retinal and Eye Research, vol. 32, pp. 102-180, 2013.

[17] R. Simo, M. Villarroel, L. Corraliza, C. Hernandez, and M. Garcia-Ramirez, "The retinal pigment epithelium: something more than a constituent of the blood-retinal barrierimplications for the pathogenesis of diabetic retinopathy," Journal of Biomedicine \& Biotechnology, vol. 2010, Article ID 190724, 15 pages, 2010.
[18] V. M. Elner, W. Scales, S. G. Elner, J. Danforth, S. L. Kunkel, and R. M. Strieter, "Interleukin-6 (IL-6) gene expression and secretion by cytokine-stimulated human retinal pigment epithelial cells," Experimental Eye Research, vol. 54, no. 3, pp. 361-368, 1992.

[19] M. L. Broadhead, S. P. Becerra, P. F. M. Choong, and C. R. Dass, "The applied biochemistry of PEDF and implications for tissue homeostasis," Growth Factors, vol. 28, no. 4, pp. 280-285, 2010.

[20] X. Liu, H. H. Chen, and L. W. Zhang, "Potential therapeutic effects of pigment epithelium-derived factor for treatment of diabetic retinopathy," International Journal of Ophthalmology, vol. 6, no. 2, pp. 221-227, 2013.

[21] B. K. Cui, S. Liu, X. J. Lin et al., "Effects of Lycium barbarum aqueous and ethanol extracts on high-fat-diet induced oxidative stress in rat liver tissue," Molecules, vol. 16, no. 11, pp. 9116-9128, 2011.

[22] C. C. Chiu, P. L. Liu, K. J. Huang et al., "Goniothalamin inhibits growth of human lung cancer cells through DNA damage, apoptosis, and reduced migration ability," Journal of Agricultural and Food Chemistry, vol. 59, no. 8, pp. 42884293, 2011.

[23] C. Y. Yen, C. C. Chiu, R. W. Haung et al., "Antiproliferative effects of goniothalamin on Ca9-22 oral cancer cells through apoptosis, DNA damage and ROS induction," Mutation Research, vol. 747, no. 2, pp. 253-258, 2012.

[24] J. Y. Kan, M. C. Yen, J. Y. Wang et al., "Nesfatin-1/nucleobindin-2 enhances cell migration, invasion, and epithelialmesenchymal transition via LKB1/AMPK/TORC1/ZEB1 pathways in colon cancer," Oncotarget, vol. 7, no. 21, pp. 31336-31349, 2016.

[25] B. D'Autreaux and M. B. Toledano, "ROS as signalling molecules: mechanisms that generate specificity in ROS homeostasis," Nature Reviews Molecular Cell Biology, vol. 8, no. 10, pp. 813-824, 2007.

[26] M. Ushio-Fukai and Y. Nakamura, "Reactive oxygen species and angiogenesis: NADPH oxidase as target for cancer therapy," Cancer Letters, vol. 266, no. 1, pp. 37-52, 2008.

[27] J. S. Clerkin, R. Naughton, C. Quiney, and T. G. Cotter, "Mechanisms of ROS modulated cell survival during carcinogenesis," Cancer Letters, vol. 266, no. 1, pp. 30-36, 2008.

[28] C. R. Geest, M. Buitenhuis, M. J. A. Groot Koerkamp, F. C. P. Holstege, E. Vellenga, and P. J. Coffer, "Tight control of MEKERK activation is essential in regulating proliferation, survival, and cytokine production of CD34+-derived neutrophil progenitors," Blood, vol. 114, no. 16, pp. 3402-3412, 2009.

[29] X. Wu and X. Hua, "Targeting ROS: selective killing of cancer cells by a cruciferous vegetable derived pro-oxidant compound," Cancer Biology \& Therapy, vol. 6, no. 5, pp. 646-647, 2014.

[30] H. H. Li, J. H. Su, C. C. Chiu et al., "Proteomic investigation of the sinulariolide-treated melanoma cells A375: effects on the cell apoptosis through mitochondrial-related pathway and activation of caspase cascade," Marine Drugs, vol. 11, no. 7, pp. 2625-2642, 2013.

[31] V. Valdiglesias, S. Giunta, M. Fenech, M. Neri, and S. Bonassi, " $\gamma \mathrm{H} 2 \mathrm{AX}$ as a marker of DNA double strand breaks and genomic instability in human population studies," Mutation Research, vol. 753, no. 1, pp. 24-40, 2013.

[32] F. Roth, A. Bindewald, and F. G. Holz, "Keypathophysiologic pathways in age-related macular disease," Graefes Archive for 
Clinical and Experimental Ophthalmology, vol. 242, no. 8, pp. 710-716, 2004.

[33] J. Z. Nowak, "Age-related macular degeneration (AMD): pathogenesis and therapy," Pharmacological Reports, vol. 58, no. 3 , pp. 353-363, 2006.

[34] The Age-Related Eye Disease Study 2 (AREDS2) Research Group, "Lutein + zeaxanthin and omega-3 fatty acids for age-related macular degeneration: the Age-Related Eye Disease Study 2 (AREDS2) randomized clinical trial," JAMA, vol. 309, no. 19, pp. 2005-2015, 2013.

[35] Age-Related Eye Disease Study Research Group, “A randomized, placebo-controlled, clinical trial of high-dose supplementation with vitamins $\mathrm{C}$ and $\mathrm{E}$, beta carotene, and zinc for agerelated macular degeneration and vision loss: AREDS report no. 8," Archives of Ophthalmology, vol. 119, no. 10, pp. 14171436, 2001.

[36] Y.-S. Ho, K.-F. So, and R. Chang, "Drug discovery from Chinese medicine against neurodegeneration in Alzheimer's and vascular dementia," Chinese Medicine, vol. 6, no. 1, p. 15, 2011.

[37] H. C. Chan, R. Chuen-Chung Chang, A. Koon-Ching Ip et al., "Neuroprotective effects of Lycium barbarum Lynn on protecting retinal ganglion cells in an ocular hypertension model of glaucoma," Experimental Neurology, vol. 203, no. 1, pp. 269-273, 2007.

[38] K. Chiu, H. C. Chan, S. C. Yeung et al., "Modulation of microglia by wolfberry on the survival of retinal ganglion cells in a rat ocular hypertension model," Journal of Ocular Biology, Diseases, and Informatics, vol. 2, no. 2, pp. 47-56, 2009.

[39] K. Chiu, Y. Zhou, S. C. Yeung et al., "Up-regulation of crystallins is involved in the neuroprotective effect of wolfberry on survival of retinal ganglion cells in rat ocular hypertension model," Journal of Cellular Biochemistry, vol. 110, no. 2, pp. 311-320, 2010.

[40] S. Y. Li, D. Yang, C. M. Yeung et al., "Lycium barbarum polysaccharides reduce neuronal damage, blood-retinal barrier disruption and oxidative stress in retinal ischemia/reperfusion injury," PLoS One, vol. 6, no. 1, p. e16380, 2011.

[41] M. Ming, L. Guanhua, Y. Zhanhai, C. Guang, and Z. Xuan, "Effect of the Lycium barbarum polysaccharides administration on blood lipid metabolism and oxidative stress of mice fed high-fat diet in vivo," Food Chemistry, vol. 113, no. 4, pp. 872-877, 2009.

[42] Q. Luo, Y. Cai, J. Yan, M. Sun, and H. Corke, "Hypoglycemic and hypolipidemic effects and antioxidant activity of fruit extracts from Lycium barbarum," Life Sciences, vol. 76, no. 2, pp. 137-149, 2004.

[43] J. R. Sparrow, K. Nakanishi, and C. A. Parish, "The lipofuscin fluorophore A2E mediates blue light-induced damage to retinal pigmented epithelial cells," Investigative Ophthalmology and Visual Science, vol. 41, no. 7, pp. 1981-1989, 2000.

[44] L. Tang, S. Bao, Y. du et al., "Antioxidant effects of Lycium barbarum polysaccharides on photoreceptor degeneration in the light-exposed mouse retina," Biomedicine and Pharmacotherapy, vol. 103, pp. 829-837, 2018.

[45] F. Liu, J. Zhang, Z. Xiang et al., "Lycium barbarum polysaccharides protect retina in $\mathrm{rd} 1$ mice during photoreceptor degeneration," Investigative Ophthalmology and Visual Science, vol. 59, no. 1, pp. 597-611, 2018.

[46] H. Li, Y. Liang, K. Chiu et al., "Lycium barbarum (wolfberry) reduces secondary degeneration and oxidative stress, and inhibits JNK pathway in retina after partial optic nerve transection," PLoS One, vol. 8, no. 7, p. e68881, 2013.

[47] N. C. Lin, J. C. Lin, S. H. Chen, C. T. Ho, and A. I. Yeh, "Effect of goji (Lycium barbarum) on expression of genes related to cell survival," Journal of Agricultural and Food Chemistry, vol. 59, no. 18, pp. 10088-10096, 2011.

[48] S. Agarwal, A. Yadav, and R. K. Chaturvedi, "Peroxisome proliferator-activated receptors (PPARs) as therapeutic target in neurodegenerative disorders," Biochemical and Biophysical Research Communications, vol. 483, no. 4, pp. 1166-1177, 2017.

[49] C. Lee, "Collaborative power of Nrf 2 and PPAR $\gamma$ activators against metabolic and drug-induced oxidative injury," Oxidative Medicine and Cellular Longevity, vol. 2017, 14 pages, 2017.

[50] T. L. Lau, C. Kim, M. H. Ginsberg, and T. S. Ulmer, "The structure of the integrin $\alpha \mathrm{IIb} \beta 3$ transmembrane complex explains integrin transmembrane signalling," EMBO Journal, vol. 28, no. 9, pp. 1351-1361, 2009.

[51] Y. Li, T. Zou, L. Xue, Z. Q. Yin, S. Huo, and H. Xu, “TGF- $\beta 1$ enhances phagocytic removal of neuron debris and neuronal survival by olfactory ensheathing cells via integrin/MFG-E8 signaling pathway," Molecular and Cellular Neuroscience, vol. 85, pp. 45-56, 2017.

[52] J. W. Fawcett, "An integrin approach to axon regeneration," Eye, vol. 31, no. 2, pp. 206-208, 2017.

[53] K. Takeda and S. Akira, "Toll-like receptors in innate immunity," International Immunology, vol. 17, no. 1, pp. 1-14, 2005.

[54] G. Dvoriantchikova, D. J. Barakat, E. Hernandez, V. I. Shestopalov, and D. Ivanov, "Toll-like receptor 4 contributes to retinal ischemia/reperfusion injury," Molecular Vision, vol. 16, pp. 1907-1912, 2010.

[55] S. Lehnardt, L. Massillon, P. Follett et al., "Activation of innate immunity in the CNS triggers neurodegeneration through a Toll-like receptor 4-dependent pathway," Proceedings of the National Academy of Sciences of the United States of America, vol. 100, no. 14, pp. 8514-8519, 2003.

[56] Z. Yang, C. Stratton, P. J. Francis et al., "Toll-like receptor 3 and geographic atrophy in age-related macular degeneration," New England Journal of Medicine, vol. 359, no. 14, pp. 14561463, 2008.

[57] U. K. Hanisch, T. V. Johnson, and J. Kipnis, “Toll-like receptors: roles in neuroprotection?," Trends in Neurosciences, vol. 31, no. 4, pp. 176-182, 2008.

[58] A. K. Patel and A. S. Hackam, "A novel protective role for the innate immunity Toll-like receptor 3 (TLR3) in the retina via stat 3," Molecular and Cellular Neuroscience, vol. 63, pp. 3848, 2014.

[59] M. Bsibsi, C. Persoon-Deen, R. W. H. Verwer, S. Meeuwsen, R. Ravid, and J. M. van Noort, "Toll-like receptor 3 on adult human astrocytes triggers production of neuroprotective mediators," Glia, vol. 53, no. 7, pp. 688-695, 2006.

[60] S. Y. Jeong, R. Jeon, Y. K. Choi et al., “Activation of microglial Toll-like receptor 3 promotes neuronal survival against cerebral ischemia," Journal of Neurochemistry, vol. 136, no. 4, pp. 851-858, 2016.

[61] S. K. Chintala, N. Putris, and M. Geno, "Activation of TLR3 promotes the degeneration of retinal ganglion cells by upregulating the protein levels of JNK3," Investigative Ophthalmology and Visual Science, vol. 56, no. 1, pp. 505-514, 2015.

[62] M.-L. Gao, K.-C. Wu, W.-L. Deng et al., "Toll-like receptor 3 activation initiates photoreceptor cell death in vivo and 
in vitro," Investigative Opthalmology \& Visual Science, vol. 58, no. 2, p. 801, 2017.

[63] X. Li, S. Jiang, and R. I. Tapping, "Toll-like receptor signaling in cell proliferation and survival," Cytokine, vol. 49, no. 1, pp. 1-9, 2010.

[64] W. W. Chou, K. C. Chen, Y. S. Wang, J. Y. Wang, C. L. Liang, and S. H. H. Juo, "The role of SIRT1/AKT/ERK pathway in ultraviolet $\mathrm{B}$ induced damage on human retinal pigment epithelial cells," Toxicology In Vitro, vol. 27, no. 6, pp. 17281736, 2013. 


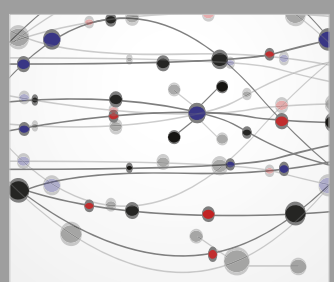

The Scientific World Journal
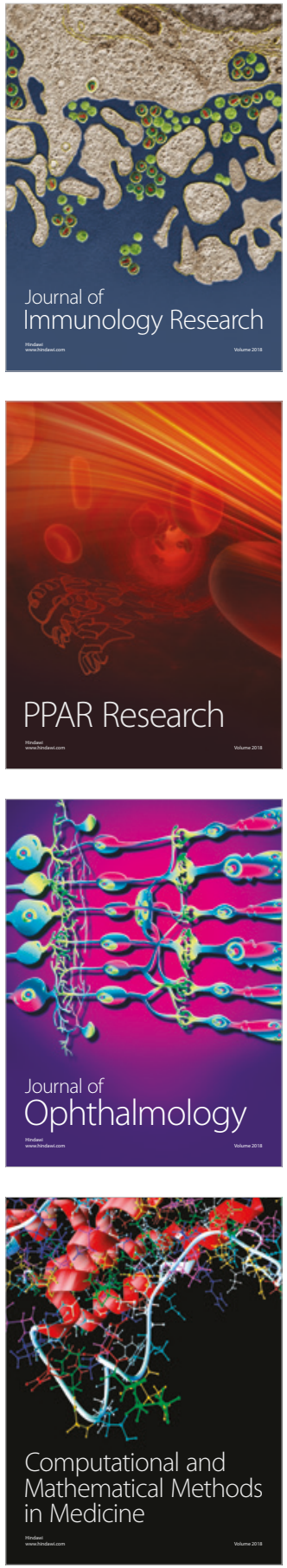

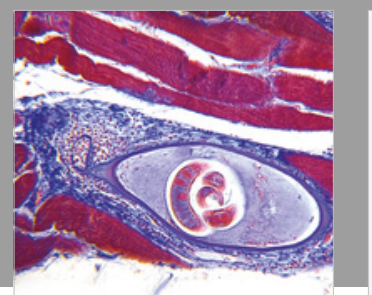

Gastroenterology Research and Practice

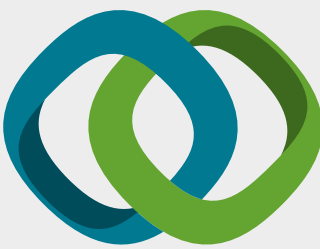

\section{Hindawi}

Submit your manuscripts at

www.hindawi.com
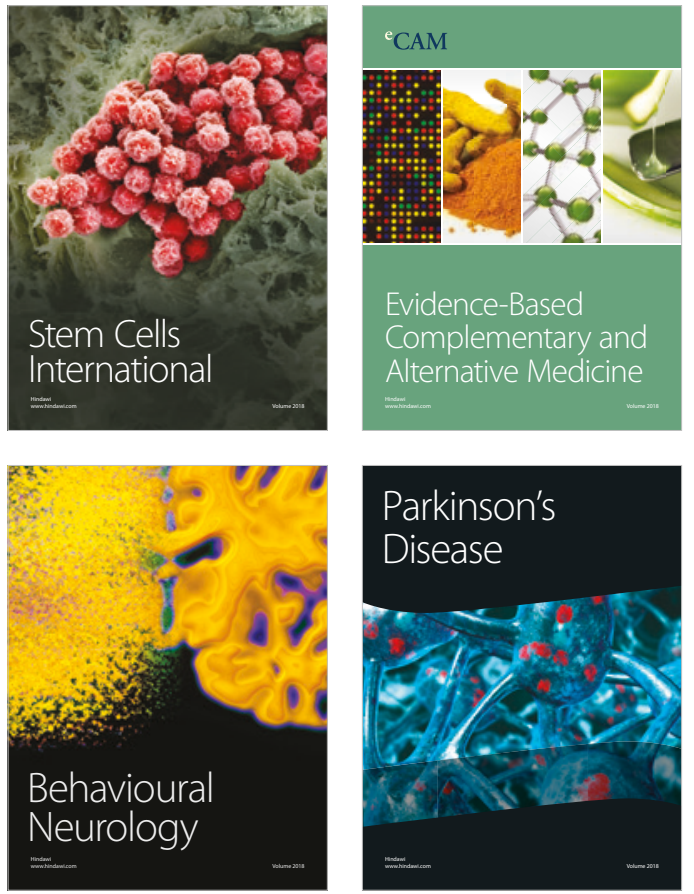

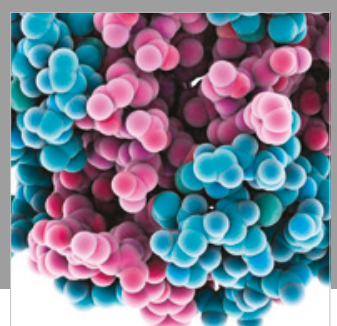

ournal of

Diabetes Research

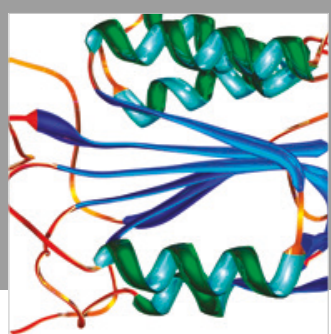

Disease Markers
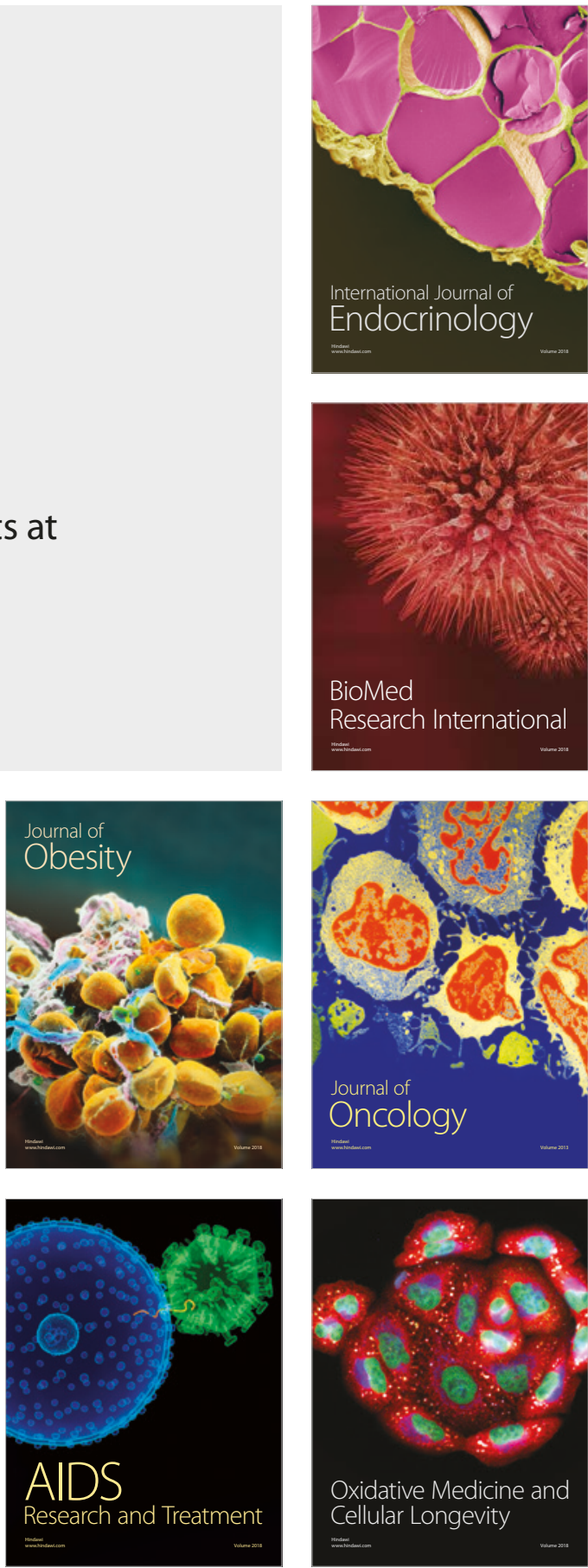